\title{
The Development of CyberLearning in Dual-Mode Higher Education Institutions in Taiwan
}

\author{
Yau-Jane Chen \\ National Chung Cheng University
}

\begin{abstract}
Open and distance education in Taiwan has evolved into the third phase - cyberlearning - conceptualized as teaching and learning interactions mediated entirely through the application of state-of-the-art information and communications technologies (ICT), such as the Internet and World Wide Web (WWW). Socio-economic influences, the development of new technologies and a marked shift in learning paradigms have increased the utilization of ICT at all levels of the Taiwanese education system. Since the advent and provision of cyberlearning programs, well over half ( 56 percent) of the conventional universities and colleges have been upgraded to dual-mode higher educational institutions. They offer real-time multicast instructional systems using videoconferencing and cable TV technology, virtual classroom systems via network-based instructional management systems, and curriculum-on-demand systems utilizing video-on-demand technology. Critical success factors in the development of these cyber universities and the opportunities, challenges and implications inherent in these are analyzed. ICT and the provision of cyberlearning have gradually been changing the structure and vision of higher education institutions as well as the entire learning environment and educational systems. Because the Ministry of Education (MOE) has initiated a policy on credit-based degrees for cyberlearning courses/programs, the development of open and distance education is anticipated to hasten the transformation of Taiwan's education system towards one which will create an ideal learning society in the 21st century.
\end{abstract}

\section{Introduction}

Distance education has been identified as one of the key strategies for educational reform and national development in Taiwan (Ministry of Education, 1996a). "Education over the air," or "distance education," is the most commonly used term to describe teaching and learning from a distance in this country. With increased applications of information and communications technologies (ICT) in this field, other terms being used to refer to distance education include "interactive distance education" (Chu, 1999), "Web learning" (Lee, 1997), "virtual education" (Farrell, 1999a) and "cyberlearning" (Han \& Wang, 1999). 
The Development of CyberLearning in Dual-Mode Higher Education

Institutions in Taiwan

\section{Definitions of Cyberlearning}

Among the aforementioned terms, "cyberlearning" is perhaps the least common. However, some newly created institutions - the dual-mode universities and colleges - have begun to describe themselves as cyber universities. Cyberlearning is focused on those teaching and learning interactions mediated entirely through the application of state-of-the-art ICT, such as the Internet and WWW (Chen, 2001).

\section{Cyber Education Institutions}

Accordingly, a cyber university is identified as an organization that uses ICT to deliver programs and courses either as a direct provider of learning opportunities to students or, without being involved itself as a direct provider of instruction, has been created through alliances/partnerships with universities/colleges or corporations to facilitate teaching and learning for participants. Such institutions typically use ICT for other core activities as:

- Administrative services, including program marketing, registration, student records, fee payments, etc.

- Teaching material development, production and distribution.

- Course delivery and tutoring.

- Career counseling/advising.

- Prior learning assessments and examinations.

In Taiwan, the use of the term cyberlearning may be gaining popularity in light of the fact that over 56 percent of higher education institutions, including many well-established conventional universities and colleges, are currently providing distance education programs with ICT and are, at the same time, rapidly moving toward Web-based delivery. Instead of using "education over the air," currently the most common term to describe teaching and learning at a distance in Taiwan, the author instead chooses "distance education" to describe open and distance education in Taiwan in general, and "cyberlearning" to refer to distance learning via ICT in particular.

International Review of Research in Open and Distance Learning 


\section{Context and Evolution of the Development of Distance Education}

Although the history of distance education in Taiwan dates back to the mid1960s, distance learning at the university level was not initiated until the establishment of The National Open University (NOU), Taiwan in 1986. Almost a decade later, conventional universities and colleges using ICT began to participate in the provision of cyberlearning. There are basically three generations in the development of distance education in Taiwan.

1966 - 1985. Taiwan's Ministry of Education (MOE) first introduced distance education in 1966 with the initiation of the Educational Radio Station and a trial of "School over the Air." In 1971, "High School over the Air" - the first open learning institution in Taiwan - was also established by the MOE. Two years later, teacher education programs were broadcast to some junior colleges via the radio to meet the urgent needs of elementary school teachers. In 1977, the "Junior College over the Air" was established to offer alternative schooling and supplementary education for adults. Correspondence and broadcasting via both radio and television served as the main media for course delivery in this stage. To provide feedback and teacher-learner interactions, such instruction was backed-up with a limited number of face-to-face tutoring sessions.

In this generation, distance education programming was offered by primary and secondary schools and junior colleges. The principal purposes of such programs in this period were mainly to provide: (a) basic education by means of an alternative medium for citizens who had less than nine years of schooling and were past school-leaving age; and (b) to offer learning opportunities for the general public who wished to study beyond the nine-year compulsory education level.

1986 - 1994. The second generation of distance education in Taiwan began in 1986 with the launch of the National Open University, established by the MOE as the first independent open learning institution in Taiwan. "Education over the Air" became popular and has been widely utilized in Taiwan since then. By the mid 1990s, the NOU was already being operated with national mandates. With enrollments of over 100,000 students in both its degree or non-degree programs, this puts the NOU into the category Daniel (1996) calls a "megauniversity." NOU, therefore, represents a rare discontinuity in the evolution of higher education, not only in terms of the scale of their operations, but also in their use of open and flexible admission policies, pedagogy, logistics and technology to dramatically increase university capacity and achieve economies of scale (Latchem, Abdullah \& Ding, 1999).

During this stage, broadcast radio and television were still the major media of instruction, with the latter becoming dominant in the 1980s. Radiophonic instruction was supported by print material and in-class tutoring provided at

International Review of Research in Open and Distance Learning 
NOU's 13 learning centers located throughout the country. But as the average education level of the general public climbed above the secondary level, the emphasis of distance education switched from basic education to university level courses delivered via continuing education, leading even more importantly to lifelong learning. That is, distance education systems were being planned as a source for lifelong education, thereby catering to a mix of adult learners and school leavers.

1995 - 2001. The third generation of distance education in Taiwan began in 1995, with the advent of advanced computer mediated communication (CMC) to provide cyberlearning. The genesis of this generation coincided with the Taiwanese government policies of upgrading the information industry and the National Science Council's effort to develop the National Information Infrastructure (NII) Project in the early '90s (Chu, 1999). Under the framework of the NII Project, three types of cyberlearning systems in Taiwan's higher education institutions were born: (a) real-time multicast instructional systems using videoconferencing and cable TV technology, (b) virtual classroom systems via network based instructional management systems, and (c) curriculum-ondemand systems utilizing video-on-demand technology (Ministry of Education, 1996b).

In the current stage, conventional higher education institutions, rather than open learning institutions, have been playing a leading role in providing distance education programs in Taiwan. Universities and colleges began experimenting with cross-university courses through real-time multimedia in 1995. By the fall of 2000, of the 153 universities and colleges in Taiwan, 85 institutions (56 percent), including many established schools, were providing distance education programs via ICT and moving rapidly to Web-based delivery (Table 1). Meanwhile, 150 videoconferencing courses and 100 Web-based courses, either entirely online or supplementary for classroom instruction, were being offered. Consequently, as conventional universities increased their provision of cyberlearning programs, the total enrollment of registered students at the NOU declined by 20 percent in the late 1990. To response to this challenge, in 1999 the NOU began to replace face-to-face instruction sessions at remote sites where the number of participants engaged in real-time-multicast and Web-based courses were low. This set-up differs from cyberlearning programs offered by conventional universities and colleges in that the NOU's pool of participants are comprised of both on-campus students and non-traditional learners with full-time jobs. The focus of cyberlearning at this stage is not only to improve in-class instruction, but also to meet the requirements of continuing professional education.

Socio-Economic Factors: All of the aforementioned distance education program initiatives have been financially supported by the MOE. Since the early 1990 s, the MOE has promoted lifelong learning, and to this end has been implementing many action strategies such as the Medium-Term Distance Education Plan, 1997-2000. As shown in Table 2, in the 1996/97 academic-year, this plan 
The Development of CyberLearning in Dual-Mode Higher Education Institutions in Taiwan

budgeted over US $\$ 19$ million in an effort to build up distance education systems in higher education institutions through the use of telecommunication technologies within a lifelong learning framework (Ministry of Education, 1996c). Funding was granted for six aspects, namely international cooperation and technology development, course development and experiment, establishment of infrastructure, corporate participation, international telecommunication fees and domestic telecommunication fees. Extra-institutional financial support from the MOE has been a highly instrumental, if not the most important, factor contributing to the development of cyberlearning in universities and colleges.

Table 1. Number of Dual-Mode Universities and Colleges and Distance Education Courses, Fall 2000

\begin{tabular}{|l|c|c|c|}
\hline & $\begin{array}{l}\text { Number of } \\
\text { Institutions }\end{array}$ & $\begin{array}{c}\text { Institutions } \\
\text { offering DE } \\
\text { Programs }\end{array}$ & $\begin{array}{c}\text { Total } \\
\text { Percentage }\end{array}$ \\
\hline $\begin{array}{l}\text { National } \\
\text { Universities }\end{array}$ & 26 & 22 & 85 percent \\
\hline $\begin{array}{l}\text { Private } \\
\text { Universities }\end{array}$ & 28 & 23 & 82 percent \\
\hline $\begin{array}{l}\text { National 4 } \\
\text { Year College }\end{array}$ & 25 & 10 & 40 percent \\
\hline $\begin{array}{l}\text { Private 4 Year } \\
\text { Colleges }\end{array}$ & 50 & 24 & 48 percent \\
\hline $\begin{array}{l}\text { National 2 } \\
\text { year Colleges }\end{array}$ & 4 & 0 & 0 percent \\
\hline $\begin{array}{l}\text { Private 2 year } \\
\text { Colleges }\end{array}$ & 20 & 85 & 56 percent \\
\hline \begin{tabular}{l} 
Total: \\
\hline
\end{tabular} & 153 & 20 percent \\
\hline
\end{tabular}

As is the case in other regions of the globe, Taiwanese higher education institutions face common challenges in terms of limited financial resources, diverse learning needs and learning styles, increased demand for more accessible programs with preferred content and increased competition from other education

International Review of Research in Open and Distance Learning 
providers (Farrell, 1999b). To cope, many Taiwanese universities and colleges have stepped up efforts to utilize ICT in order to reduce costs, increase enrollments, enrich the quality of on-campus instruction, improve the quality of current distance learning, enhance access to instructional resources, and gain an edge over competitive forces. Taiwanese distance education is affected by two additional factors: the development of ICT and a shift in learning paradigms.

Influence of ICT Development on Distance Education. The application of multimedia and Internet applications in distance learning are potentially hindered by obstacles such as computer access, electronic communication software, insufficient bandwidth, and a lack of supplementary learning resources. Affordable rates for online learning, learner skills in the use of electronic communication software, extensive readings of print on the Internet etc., also hold implications for the evolution of distance learning. As a result, text-based materials still dominate the content format. Yet as technical, financial and learner issues continue to improve, distance education in Taiwan is anticipated to evolve rapidly.

Shift in Learning Paradigms. From the perspective of the teacher-centered learning paradigm, ICT was initially used to facilitate the design and delivery of instruction for teachers. Accordingly, teacher-directed models such as telecourses and teleconferences, were the two primary modes of distance learning for decades. In the mid-1990s, ICT came to be regarded in Taiwan, as a tool to stimulate learner initiative and control and to enhance students' responsibility for their own learning. Therefore, a new learning paradigm using ICT to facilitate learning to improve student competencies in knowledge construction, critical thinking, teamwork and collaborative learning, has become the predominant approach to cyberlearning.

\section{Examples of Dual-Mode Universities}

A growing number of conventional universities and colleges are now dual-mode institutions, catering to the needs of on-campus students as well as off-campus learners. In Taiwan, where there is a long-standing tradition of university-level extension education, many universities and colleges provide both on-campus courses and extension education programs, particularly continuing professional education programs via such cyberlearning modes as videoconferencing and Web-based instruction.

Real-Time Multicast. Utilizing videoconferencing and cable TV technology to link a master classroom to one or more remote sites with two-way audio-video transmissions, real-time multicast instructional systems comprised the major distance learning model in the late 1990s. Allowing for synchronous interaction between instructor and learners and among learners, this type of delivery was

International Review of Research in Open and Distance Learning 
adapted to promote cross-institution courses - that is, providing opportunities for students to take courses from other universities that were not offered in their own school.

Established national universities (Taiwan University, Chin Hwa University, Chiao Tung University, Cheng Kung University and Chung Cheng University) began to offer inter-university courses via real-time multicast in the 1995-96 academic year. Other universities followed suit the next year. As shown in Table 3, the number of dual-mode higher education institutions and cybercourses offered increased dramatically from 1997 to 2000 . Of the 153 conventional universities and colleges in Taiwan, 95 institutions (62 percent) offered cyberlearning programs from 1995 to 2000 (an increase of 217 percent since 1997). Distance education courses taught via ICT increased from 22 to 150 in three years. With advancement of network-based communication technologies, the MOE announced that although it would stop funding real-time multicast programs, it would continue to support Web-based courses from 2001 onward (Ministry of Education, 2000).

*Including Spring and Fall 2000

The Emergence of Cyberlearning Organizations. The integration of powerful instructional environments of cyberlearning (Internet systems, multimedia software, database technology, network information retrieval, computermediated interaction, general communication interface, HTML and JAVA, and Web-based information delivery) simulates classroom settings in which the instructor interacts with learners synchronously. This level of technological integration also enables learners to comment, for example, on reading materials and to discuss with one another asynchronously without attending scheduled class meetings. In a synchronous system, learners communicate in real-time in written or verbal form, depending on the system configuration. By posting messages, students share ideas, raise questions, and receive feedback online asynchronously and simultaneously. Web-based learning systems also enable learners to send assignments via e-mail, or upload the system interface to take exams via the platform. Learning resources, such as online libraries and related Web sites, can also be hyperlinked to course pages. Some virtual classroom systems even have a built-in virtual learning companion to study with the learner (Chao \& Huang, 1997). Given all the tools and functions, the Web-based instructional system creates a meaningful, collaborative learning environment for students.

In addition, curriculum-on-demand systems are also network-based systems that allow remote access to instructional software and materials. Students select desired courses from a menu listing those that are available. However, the types of interactivity available depend on the design of the courseware. Video-ondemand technology is required to support multimedia and course-on-demand courseware. Compared with real-time multimedia and Web-based instructional systems, course-on-demand systems provide low-level learning activities because they only allow for interaction between the learner and the software.

International Review of Research in Open and Distance Learning 
The Development of CyberLearning in Dual-Mode Higher Education

Examples of cyberlearning organizations in Taiwan include:

Taiwan University (http://ceiba3.cc.ntu.edu.tw. )

Sun-Yat-Sen University (http://cu.nsysu.edu.tw. )

Chung Cheng University (http://server2.webedu.ccu.edu.tw. )

Chiao Tung University (http://e.nctu.edu.tw/index_new.php. )

Chin Hwa University (http://www.nthu.edu.tw/teaching/teach.html. )

Cheng Kung University (http://www.ncku.edu.tw/^media. )

Central University (b¿http://www.ncu.edu.tw/cnormal/admini/admini.html. )

Cheng Chi University (http://www.elearn.nccu.edu.tw. )

Tainan Teachers' College (http://linc.hinet.net. )

Yuan Ze University (http://www.yzu.edu.tw. )

Except Yuan Ze, all the universities or colleges listed above are national in scope. The first few institutions in Taiwan to begin experimenting with courseon-demand systems include Chung Cheng University, Sun-Yat-Sen University, Yuan Chi University and the Tai Chun National Science Museum. Cyberlearning courses offered by these institutions have now been expanded to include industries desirous of providing on-the-job training opportunities for their employees, and to a variety of other bodies wishing to offer continuing professional education.

Cyberlearning Programs for Nontraditional Students - The SYSU Case. Among the dual-mode higher education institutions, Sun-Yat-Sen University (SYSU) is a typical example of a university that offers cyberlearning courses to professionals. In the fall of 1999, SYSU introduced cyberlearning courses for professionals in the fields of information management, finance management and e-commerce. As shown in Table 4, a total of 37 courses taught by 27 instructors was provided to 3,844 adult learners from 1999 to 2001.

International Review of Research in Open and Distance Learning 
Of all the SYSU cyberlearning courses, the Information Management Program is the most popular, comprising over one fourth of total enrollment of the SYSU distance learners. The Department of Information Management completed the design and development of nine online core courses within two years. Table 5 shows that as the number of courses increased, along with enrollments (23 percent in 2000 and 41 percent in 2001). Tables 6, 7, and 8 show that participants are located in all regions of the country and represent variety of backgrounds in terms of age and education levels.

According to the SYSU Information Management program planner, institutional support is the most important factor contributing to the success program. Toplevel administrators of SYSU encourage faculty members and staff to develop Web-based courses, providing them with sufficient technical support and incentive mechanisms to design and conduct programs. Program marketing and promotion also enhance public awareness, thus increasing enrollment. In addition, training and professional development to facilitate cyberlearning have been provided to faculty and staff, helping improve the quality of instruction. Since 2001, SYSU has expanded its cyberlearning programs to China in collaboration with Beijing University.

\section{Implications}

Although the development of cyberlearning in dual-mode higher education institutions began a few years ago in Taiwan, critical factors that appear to favor successful adoption of ICT in universities and colleges include:

- Taiwan governmental policies toward upgrading the information industry and the National Science Council's effort to launch and promote the NII Project in the early ' 90 s.

- Financial resources from the MOE to initiate the distance education experiment via ICT in 1995, backed by its ongoing efforts to support cyberlearning programs.

- Partnerships involving higher education institutions and the private sector in the development and delivery of cyberlearning courses.

- Delivery formats that are appropriate for, and accepted by, the target audience.

- Accreditation in the form of credits and degrees, which serve as a motivating force and an impetus in the development of industry standards.

The implications of cyberlearning in dual-mode universities and colleges present a variety of opportunities and challenges for Taiwan's distance education sector in the future. Opportunities include:

International Review of Research in Open and Distance Learning 
The Development of CyberLearning in Dual-Mode Higher Education Institutions in Taiwan

- Increasing the number and types of courses to meet online learning needs.

- More cyberlearning programs for both on-campus and off-campus participants.

- Greater potential for learners to interact with students from around the globe.

- Measures to improve the quality of course design and learning outcomes.

- Better provision of computer and network skills.

Besides some technological issues, such as limited network bandwidth and expensive network fees, challenges also include:

- Technology-driven rather than need-oriented course design.

- Resistance by some faculty and administrators.

- Lack of clear evaluation criteria for cyber instruction and learning.

- Concern over inadequate socialization opportunities for some learners.

- Problems of equity in terms of access to computers and networks.

\section{Conclusions}

ICT and the provision of cyberlearning are changing the structure and vision of higher education institutions in Taiwan. With the current MOE policy of accreditation, which only offers course credits in programs leading to full degrees, the development of open and distance education is anticipated to swiftly move Taiwan closer and closer towards the goal of becoming a model learning society in the 21st century. 
The Development of CyberLearning in Dual-Mode Higher Education

Institutions in Taiwan

\section{References}

Chao, M. S. \& Huang, R. H. (1997). A Case Study of a Broad-band Network Real-time Multicast System: The Development of National Chung Cheng University Distance Learning Pilot System. Journal of Information and Education, 58: 30-38.

Chen, Y. J. (2001). Cyber University and Adult Learning. Adult Education Bimonthly, 59: 30-39.

Chu, C. T. (1999). The Development of Interactive Distance Learning in Taiwan: Challenges and Prospects. Educational Media International, 36(2): 110-114.

Daniel, J. (1996). Mega-universities and Knowledge Media: Technology Strategies for Higher Education. London: Kogan Page.

Farrell, G. M. (1999a). The Development of Virtual Education: A Global Perspective. The Commonwealth of Learning, Canada.

Farrell, G. M. (1999b) The Development of Virtual Institutions in Canada. The Commonwealth of Learning, Canada.

Han, H. W. \& Wang, Y. C. (1999). Lifelong Cyberlearning System: A Pilot Project for the Learning Society in the ROC. Educational Media International, 36(2): 115-120.

Latchem, C., Abdullah, S., \& Ding, X. (1999). Open and Dual-Mode Universities in East and South Asia. Performance Improvement Quarterly, 12(2): $96-121$.

Lee, G. B. (1997). The Current Status and Future Trends of Web-based Training. The Navigator of Information Application, 15: 1-14.

Ministry of Education (1996a). Report on the Needs Assessment of Distance Learning. Taipei, Ministry of Education.

Ministry of Education (1996b). Report on the Plan of Development of Distance Learning Pilot Systems. Taipei, Ministry of Education.

Ministry of Education (1996c). The Medium-term Plan of the Development of the Distance Education Project. Taipei, Ministry of Education.

Ministry of Education (2000). Report on the Evaluation of the Implementation of the Distance Education Project. Taipei, Ministry of Education.

International Review of Research in Open and Distance Learning 
The Development of CyberLearning in Dual-Mode Higher Education

Institutions in Taiwan

\section{Online Resources}

Cyberlearning Systems of National Taiwan University. [Online] Available at: http://ceiba3.cc.ntu.edu.tw.

http://cu.nsysu.edu.tw. Homepage of Cyberlearning Systems of National SunYat-Sen University.

Cyberlearning Systems of National Chiao Tung University. [Online] Available at: http://e.nctu.edu.tw/index_new.php.

Cyberlearning Systems of National Tainan Teachers' College. [Online]. Available at: http://linc.hinet.net.

Cyberlearning Systems of National Chung Cheng University. [Online] Available at: http://server2.webedu.ccu.edu.tw.

Cyberlearning Systems of National Cheng Chi University. [Online] Available at: http://www.elearn.nccu.edu.tw.

Cyberlearning Systems of National Cheng Kung University. [Online] Available at: http://www.ncku.edu.tw/ media.

Cyberlearning Systems of National Central University. [Online] Available at: http://www.ncu.edu.tw/cnormal/admini/admini.html.

Cyberlearning Systems of National Chin Hwa University. [Online] Available at: http://www.nthu.edu.tw/teaching/teach.html.

Cyberlearning Systems of Yuan Ze University. [Online] Available at: http://www.yzu.edu.tw.

Citation Format

Chen, Yau-Jane (January, 2002) The Development of CyberLearning in Dual-Mode Higher Education Institutions in Taiwan. International Review of Research in Open and Distance

Learning: 2, 2. http://www.icaap.org/iuicode?149.2.2.13 
The Development of CyberLearning in Dual-Mode Higher Education Institutions in Taiwan

Table 2. MOE Grants (US\$) Medium-Term Plan of the Distance Education Project

\begin{tabular}{|l|c|c|c|c|c|}
\hline & $\mathbf{1 9 9 7}$ & $\mathbf{1 9 9 8}$ & $\mathbf{1 9 9 9}$ & $\mathbf{2 0 0 0}$ & Total: \\
\hline $\begin{array}{l}\text { International } \\
\begin{array}{l}\text { Cooperation \& } \\
\text { Technology } \\
\text { Development }\end{array}\end{array}$ & 521,739 & 415,942 & 455,072 & 475,362 & $1,868,145$ \\
\hline $\begin{array}{l}\text { Course } \\
\text { Development } \\
\text { \& Experiments }\end{array}$ & $1,484,057$ & $1,191,304$ & $1,440,579$ & $1,553,623$ & $5,669,565$ \\
\hline $\begin{array}{l}\text { Setting-up } \\
\text { Infrastructure }\end{array}$ & $2,927,536$ & 686,956 & 747,826 & 800,000 & $5,162,318$ \\
\hline $\begin{array}{l}\text { Corporate } \\
\text { Participation }\end{array}$ & 318,840 & 321,739 & 292,753 & 269,565 & $1,202,898$ \\
\hline $\begin{array}{l}\text { International } \\
\text { Telecommuni- } \\
\text { cation Fees }\end{array}$ & 173,913 & 173,913 & 231,884 & 289,855 & 869,565 \\
\hline $\begin{array}{l}\text { Domestic } \\
\text { Telecommuni- } \\
\text { cation Fees }\end{array}$ & 927,536 & 927,536 & $1,159,420$ & $1,391,304$ & $4,405,797$ \\
\hline $\begin{array}{l}\text { Total } \\
\text { Funding } \\
\text { (US\$) }\end{array}$ & $\mathbf{6 , 3 5 3 , 6 2 1}$ & $\mathbf{3 , 7 1 7 , 3 9 0}$ & $\mathbf{4 , 3 2 7 , 5 3 4}$ & $\mathbf{4 , 7 7 9 , 7 0 9}$ & $\mathbf{1 9 , 1 7 8 , 2 8 8}$ \\
\hline
\end{tabular}


The Development of CyberLearning in Dual-Mode Higher Education Institutions in Taiwan

Table 3. Increase in Institutions Providing Distance Education Courses in Taiwan 1997 to 2000*

\begin{tabular}{|l|c|c|c|}
\hline & $\mathbf{1 9 9 7}$ & $\mathbf{2 0 0 0}$ & $\begin{array}{l}\text { Increase } \\
\text { Rate } \\
\text { (\%) }\end{array}$ \\
\hline $\begin{array}{l}\text { Total Number of Taiwanese } \\
\text { Conventional } \\
\text { Universities \& Colleges }\end{array}$ & & 153 & \\
\hline $\begin{array}{l}\text { Cumulative Number of Dual-Mode } \\
\text { Institutions }\end{array}$ & 30 & $95^{*}$ & $217 \%$ \\
\hline Number of Courses & 22 & 150 & $560 \%$ \\
\hline
\end{tabular}

Table 4. Numbers of SYSU Cyberlearning Courses, Instructors \& Enrollment

\begin{tabular}{|l|l|}
\hline All Departme nts (1999-2001) & N \\
\hline Cyberlearning Courses & 37 \\
\hline Instructors & 27 \\
\hline Enrollment & 3844 \\
\hline & \\
\hline Average Enrollme nt/per course & $\mathbf{1 0 4}$ \\
\hline
\end{tabular}

Table 5. Enrollment and Participants in the IM Program, SYSU (Fall 2000)

\begin{tabular}{|l|c|c|c|}
\hline Semester & Course & Enrollme nt & $\begin{array}{c}\text { Increase } \\
\text { Rate } \\
\text { (\%) }\end{array}$ \\
\hline & & & \\
\hline Fal1 1999 & 3 & 177 & \\
\hline Spring 2000 & 6 & 217 & $23 \%$ \\
\hline Fal1 2000 & 9 & 312 & $41 \%$ \\
\hline Spring 2001 & 9 & 287 & \\
\hline Total & & $\mathbf{9 9 3}$ & \\
\hline
\end{tabular}


The Development of CyberLearning in Dual-Mode Higher Education Institutions in Taiwan

Table 6. Student Age - Fall $2000(\mathrm{~N}=312)$

\begin{tabular}{|c|c|c|}
\hline Age & Number of Students & Percentage \\
\hline $22-29$ & 156 & $50 \%$ \\
\hline $30-39$ & 115 & $37 \%$ \\
\hline $40-49$ & 35 & $11 \%$ \\
\hline $50-59$ & 6 & $2 \%$ \\
\hline
\end{tabular}

Table 7. Education Background - Fall $2000(\mathrm{~N}=312)$

\begin{tabular}{|l|c|c|}
\hline Education & Number of Students & Percentage \\
\hline 2-year College & 90 & $29 \%$ \\
\hline $\begin{array}{l}\text { University \& } \\
\text { College }\end{array}$ & 200 & $64 \%$ \\
\hline $\begin{array}{l}\text { International } \\
\text { University }\end{array}$ & 12 & $4 \%$ \\
\hline $\begin{array}{l}\text { Military } \\
\text { Schools }\end{array}$ & 10 & $3 \%$ \\
\hline
\end{tabular}

Table 8: Location of Students - Fall $2000(\mathrm{~N}=312)$

\begin{tabular}{|l|c|c|}
\hline $\begin{array}{l}\text { Learner } \\
\text { Location }\end{array}$ & Number of Students & Percentage \\
\hline $\begin{array}{l}\text { Northern } \\
\text { Taiwan }\end{array}$ & 76 & $24 \%$ \\
\hline $\begin{array}{l}\text { Central } \\
\text { Taiwan }\end{array}$ & 31 & $10 \%$ \\
\hline $\begin{array}{l}\text { Southern } \\
\text { Taiwan }\end{array}$ & 199 & $64 \%$ \\
\hline $\begin{array}{l}\text { E astern } \\
\text { Taiwan }\end{array}$ & 6 & $2 \%$ \\
\hline
\end{tabular}

International Review of Research in Open and Distance Learning 